\section{Ethnic differences in refraction and ocular biometry in a population-based sample of 11-15- year-old Australian children}

JM Ip', SC Huynh'1', D Robaei', A Kifley'1, KA Rose², IG Morgan ${ }^{3}$, JJ Wang ${ }^{1}$ and P Mitchell'

\section{Abstract}

Purpose To examine the prevalence of refractive error and distribution of ocular biometric parameters among major ethnic groups in a population-based sample of 11-15-year-old Australian children. Methods The Sydney Myopia Study examined 2353 students (75.3\% response) from a random cluster-sample of 21 secondary schools across Sydney. Examinations included cycloplegic autorefraction, and measures of corneal radius of curvature, anterior chamber depth, and axial length. Results Participants mean age was $\mathbf{1 2 . 7}$ years (range 11.1-14.4); $49.4 \%$ were female. Overall, $60.0 \%$ of children had European Caucasian ethnicity, 15.0\% East Asian, 7.1\% Middle Eastern, and 5.5\% South Asian. The most frequent refractive error was mild hyperopia (59.4\%, 95\% confidence interval (CI), 53.2-65.6), defined as spherical equivalent (SE) +0.50 to $+1.99 \mathrm{D}$. Myopia (SE-0.50 D or less) was found in $11.9 \%, 95 \%$ (CI 6.6-17.2), and moderate hyperopia $(\mathrm{SE} \geqslant+2.00 \mathrm{D})$ in $3.5 \%$, 95\% (CI 2.8-4.1). Myopia prevalence was lower among European Caucasian children (4.6\%, 95\% CI 3.1-6.1) and Middle Eastern children (6.1\%, 95\% CI 1.3-11.0) than among East Asian (39.5\%, 95\%, CI 25.6-53.5) and South Asian (31.5\%, 95\%, CI 21.6-41.4) children. European Caucasian children had the most hyperopic mean SE $(+0.82 \mathrm{D})$ and shortest mean axial length $(23.23 \mathrm{~mm})$. East Asian children had the most myopic mean SE $(-0.69 \mathrm{D})$ and greatest mean axial length $(23.86 \mathrm{~mm})$.

Conclusion The overall myopia prevalence in this sample was lower than in recent similaraged European Caucasian population samples.
East Asian children in our sample had both a higher prevalence of myopia and longer mean axial length.

Eye (2008) 22, 649-656; doi:10.1038/sj.eye.6702701; published online 2 February 2007

Keywords: myopia; ocular biometry; populationbased; epidemiology; Sydney myopia study; refraction

\section{Introduction}

Uncorrected refractive errors are a major cause of visual impairment in children worldwide, and are a priority area targeted by the World Health Organisation in the global initiative to eliminate avoidable blindness by the year $2020{ }^{1}$ The recent population-based Refractive Error Study in Children surveys collected data from six countries ${ }^{2-9}$ and reported high myopia prevalence rates in East Asian countries and in urban areas. Among children aged 12 years, the prevalence of myopia is higher in China $(18-49.7 \%)^{2,3}$ and Malaysia $(24.8 \%){ }^{4}$ than in Nepal $(2 \%),{ }^{5}$ South Africa $(4 \%),{ }^{6}$ India $(10-10.6 \%),{ }^{7,8}$ and Chile (10\%). ${ }^{9}$ In other studies, the prevalence of myopia among school children in Taiwan, Hong Kong, and Singapore ranges from 26 to $55 \% .^{10-12}$ Recent populationbased studies of refractive error among European Caucasian children are scant. ${ }^{13-15}$ In one study among children aged 12-13 years in Sweden, the prevalence of myopia was high $(49.7 \%) .{ }^{13}$ In the US, two studies have reported on the prevalence of myopia in children, although these rates have varied (9.2 and 28\%). ${ }^{14,15}$

Given the high prevalence of myopia in East Asian countries and the observation that
${ }^{1}$ Department of Ophthalmology and the Westmead Millennium Institute, Centre for Vision Research, University of Sydney, Sydney, Australia

${ }^{2}$ School of Applied Vision Sciences, Faculty of Health Sciences, University of Sydney, Sydney, Australia

${ }^{3} \mathrm{ARC}$ Centre of Excellence in Vision Science and Research School of Biological Sciences, Australian National University, Canberra, Australia

Correspondence: P Mitchell, Department of Ophthalmology, Centre for Vision Research, University of Sydney, Westmead Hospital, Hawkesbury Road,

Westmead,

New South Wales 2145, Australia

Tel: + 61298457953 ;

Fax: + 61298458345

E-mail: paul_mitchell@

wmi.usyd.edu.au

Received: 19 July 2006 Accepted in revised form: 30 November 2006 Published online: 2 February 2007

Proprietary Interest: None 
myopic eyes generally have greater axial length than non-myopic eyes, ${ }^{12,16}$ it could be postulated that ocular dimensions may differ between ethnic groups. Studies comparing ocular components by ethnicity are few, ${ }^{17,18}$ despite recent large ocular biometry data sets published for children in Singapore, Taiwan, Malaysia, Vanuatu, and the US. ${ }^{10,17-20}$ Although the IOLMaster, a commercial biometry instrument using partial coherence interferometry is more precise than clinical ultrasound in measurement of axial length, ${ }^{21}$ few studies of ocular biometry in children, however, have utilised this tool to date. ${ }^{22,23}$

In this paper, we aimed to (1) report the prevalence of refractive errors; and (2) use the IOLMaster to examine ocular biometric components in children from ethnic groups found in a large sample of Year 7 school children (predominantly aged 12 years) residing in Sydney, Australia.

\section{Materials and methods}

The Sydney Myopia Study is a population-based survey of eye health in school children resident in Sydney, Australia, and forms part of the Sydney Childhood Eye Study. Findings for 6-year-old children have been reported previously. ${ }^{23}$ Approval for the study was obtained from the Human Research Ethics Committee of the University of Sydney, the New South Wales Department of Education and the Catholic Education Office. The study adhered to the tenets of the Declaration of Helsinki.

Secondary schools across the Sydney metropolitan region were stratified by socio-economic status and 21 schools, including a proportional mix of public and private/religious schools, were selected to provide a representative sample of Sydney children. ${ }^{24}$ All children in Year 7 were invited to participate. After informed written consent from their parents, children underwent a detailed eye examination, which included cycloplegic autorefraction (RK-F1 autorefractor, Canon, Tokyo, Japan) and ocular biometry (IOLMaster, ${ }^{\mathrm{TM}}$ Carl ZeissMeditec, Jena, Germany).

Five reliable readings of refraction were generated by the autorefractor for each eye; the mean reading was used for analysis. Ocular biometry measurement included corneal radius of curvature (measured along the flattest and steepest meridians and axial length), anterior chamber depth (measured as the distance from the anterior corneal surface to the anterior lens surface), and axial length (measured as the distance from the anterior corneal vertex to the retinal pigment epithelium along the fixation line). Lens power was calculated using Bennett's formula. ${ }^{25}$
Amethocaine $0.5 \%$ (Minims $^{\mathrm{TM}}$, Chauvin Pharmaceuticals, England) was used for corneal anaesthesia at $0 \mathrm{~min}$, followed by cyclopentolate $1 \%$ (one drop) at $2 \mathrm{~min}$ for cycloplegia. Tropicamide $1 \%$ (one drop) at $3 \mathrm{~min}$ and phenylephrine $2.5 \%$ (one drop) at around $10 \mathrm{~min}$ were also used in some children to obtain adequate mydriasis. A minimum pupillary diameter of $6 \mathrm{~mm}$ was achieved in all children before refraction. Tropicamide was used in $53.0 \%$ and phenylephrine was used in $10.6 \%$ of students. Dilating eye drops were refused by 11 children $(0.5 \%)$ who consented to non-cycloplegic autorefraction and completed all other examinations. Autorefraction was performed approximately $25 \mathrm{~min}$ after the last drop.

Socio-demographic information including ethnicity, highest level of parental education, and occupation were collected in questionnaires completed by parents. Ethnicity of the child was determined only if both parents shared that ethnic origin. Otherwise, children were placed in the mixed ethnicity category. Ethnicity was classified on the basis of self-identification by the parents, combined with information about the place of birth of the child. Ethnic categories (European Caucasian, East Asian, South Asian, Middle Eastern, Pacific Islander, Indigenous Australian, African, South American) were consistent with the Australian Standard Classification of Cultural and Ethnic groups (available at www.abs.gov.au, document number 1249.0), which takes into consideration the similarity in the cultural and social characteristics to determine ethnic groupings. The term East Asian covers people originating from China, Malaysia, Singapore, Indonesia, Philippines, Japan, Korea, Myanmar, Thailand, Laos, Cambodia, and Vietnam. The broad classification of East Asian was used rather than separate Northeast Asian and Southeast Asian categories because of the difficulty in classifying people derived from both of these branches. South Asian included people originating from India, Pakistan, and Nepal.

Myopia was defined as spherical equivalent (SE) refraction (sphere $+\frac{1}{2}$ cylinder) $-0.50 \mathrm{D}$ or less, emmetropia as SE -0.49 to $+0.49 \mathrm{D}$, mild hyperopia as $\mathrm{SE}+0.50$ to $+1.99 \mathrm{D}$, and moderate hyperopia as $\mathrm{SE}+2.00 \mathrm{D}$ or greater.

Data were analysed using Statistical Analysis System software (SAS Institute, Cary, NC, USA). Overall distributions of refraction and ocular biometric parameters were described in terms of central tendency and spread (mean and SD). Mixed models and generalised estimating equations were used to examine associations and subgroup differences, adjusting for the effects of cluster sampling. Where cluster effects were not significant, $t$-tests and $\chi^{2}$ tests were used. All confidence intervals (CIs) are $95 \%$. Average corneal radius of 
curvature was the average of the steepest and flattest meridians. Axial length/corneal radius (AL/CR) ratio was defined using the average corneal radius of curvature.

\section{Results}

\section{Population characteristics}

Overall, 2353 children were examined (75.3\% response); participants and non-participants were similar in gender and ethnic background (Table 1). The mean age of participants was 12.7 years, ranging from 11.1 to 14.4 years, with $49.4 \%$ girls. Among participants, most were of European Caucasian ethnicity $(60.0 \%)$, other ethnicities included East Asian (15.0\%), Middle Eastern (7.1\%), South Asian (5.5\%), and Oceanian (3.3\%). Mixed

Table 1 Demographic characteristics of participants $(n=2353)$ and non-participants $(n=777)$

\begin{tabular}{|c|c|c|}
\hline & \multicolumn{2}{|c|}{ Participants n $(\%)^{\mathrm{a}}$ Non-participants n (\%) } \\
\hline \multicolumn{3}{|l|}{ Gender } \\
\hline Girls & $1163(49.4)$ & $376(48.4)$ \\
\hline Boys & $1190(50.6)$ & $401(51.6)$ \\
\hline \multicolumn{3}{|l|}{ Ethnicity } \\
\hline European Caucasian & $1407(60.0)$ & $527(67.8)$ \\
\hline Other $^{b}$ & $938(40.0)$ & $250(32.2)$ \\
\hline \multicolumn{3}{|l|}{ School type } \\
\hline Public & $1971(83.8)$ & $630(82.8)$ \\
\hline Private & $382(16.2)$ & $131(17.2)$ \\
\hline \multicolumn{3}{|c|}{$\begin{array}{l}\text { aAge of participants included } 11-12 \text { years }(4.3 \%), 12-13 \text { years }(69.9 \%), 13- \\
14 \text { years }(25.6 \%) \text {, and } 14-15 \text { years }(0.2 \%) \text {. } \\
\text { bOther ethnic groups of participants included East Asian (15\%), Middle } \\
\text { Eastern }(7.1 \%) \text {, South Asian }(5.5 \%) \text {, Oceanian }(3.3 \%) \text {, and mixed ethnicity } \\
(7.6 \%) \text {. African, Indigenous and South American ethnic groups each } \\
\text { comprised }<1 \% \text {. }\end{array}$} \\
\hline
\end{tabular}

ethnicity accounted for $7.6 \%$, and other ethnicities (African, indigenous, South American) each comprised less than $1 \%$.

\section{Refractive error and refraction}

Overall, the vast majority of children had mild hyperopia $(59.4 \%$, Table 2$)$, which was followed by emmetropia $(25.3 \%)$ and myopia (11.9\%), including $8.0 \%$ who had myopia of SE less than $-1.00 \mathrm{D}$. Moderate hyperopia was found in $3.5 \%$. The mean SE for the whole group was emmetropic ( +0.49 D; Table 3).

Children in the European Caucasian and Middle Eastern subgroups had lower prevalence rates of myopia (4.6 and $6.1 \%$, respectively) than children of East Asian and South Asian ethnicity (39.5 and 31.5\%, respectively). Mean SE was more myopic among the East Asian (-0.69 D) and South Asian groups (-0.35D) compared to the European Caucasian $(+0.82 \mathrm{D})$ and Middle Eastern groups ( $+0.71 \mathrm{D}$, Table 3 ). Children of European Caucasian ethnicity had significantly more hyperopic SE $(+0.82 \mathrm{D})$ than children from other ethnic backgrounds combined $(+0.04 \mathrm{D}, P<0.0001)$ after adjusting for age, gender, and height. Girls had a significantly higher prevalence of myopia than boys (14.1 vs 9.7\%), with less hyperopic mean SE ( + 0.39D vs + 0.58D).

\section{Corneal radius of curvature and axial length}

Mean corneal radius was steeper in children of European Caucasian ethnicity and South Asian ethnicity than in children of other ethnic groups (Table 3). Mean axial length was shorter in the European Caucasian and the Middle Eastern subgroups (Table 3 ). Boys had slightly flatter corneas (7.84 vs $7.73 \mathrm{~mm}, P<0.0001)$ and longer eyes (23.72 vs $23.30 \mathrm{~mm}, P<0.0001)$ than girls.

Table 2 Proportion (95\% CI) of children with refractive error, stratified by gender and ethnicity, adjusting for the effects of clustersampling

\begin{tabular}{lccccc}
\hline & $\mathrm{n}$ & Moderate hyperopia & Mild hyperopia & Emmetropia & Myopia \\
\hline Whole group & 2340 & $3.5(2.8-4.1)$ & $59.4(53.2-65.6)$ & $25.3(22.1-28.4)$ & $11.9(6.6-17.2)$ \\
Girls & 1154 & $3.3(2.2-4.4)$ & $59.1(52.1-66.1)$ & $23.5(19.7-27.3)$ & $14.1(8.4-19.8)$ \\
Boys & 1186 & $3.6(2.6-4.7)$ & $59.7(53.3-66.1)$ & $27.0(23.0-31.0)$ & $9.7(4.5-14.9)$ \\
European Caucasian & 1402 & $4.4(3.6-5.3)$ & $69.9(66.6-73.2)$ & $21.0(18.0-24.1)$ & $4.6(3.1-6.1)$ \\
East Asian & 349 & $1.1(0.2-2.1)$ & $25.2(19.0-31.4)$ & $34.1(24.3-43.9)$ & $39.5(25.6-53.5)$ \\
South Asian & 127 & $0.0(-)$ & $33.9(21.1-46.7)$ & $34.6(25.2-44.1)$ & $31.5(21.6-41.4)$ \\
Middle Eastern & 163 & $6.1(1.5-10.7)$ & $63.8(59.5-68.1)$ & $23.9(18.9-29.0)$ & $6.1(1.3-11.0)$ \\
Mixed ethnicity & 112 & $1.7(0.0-3.6)$ & $57.0(48.0-65.9)$ & $30.2(22.9-37.4)$ & $11.2(5.3-17.0)$ \\
\hline
\end{tabular}

D, dioptre; SE, spherical equivalent refraction.

${ }^{a}$ Data not presented for smaller ethnicities including Oceanian, African, Indigenous, and South American. East Asian includes the following ethnicities: China, Malaysia, Singapore, Indonesia, Philippines, Japan, Korea, Myanmar, Thailand, Laos, Cambodia, and Vietnam. South Asian includes India, Pakistan, and Nepal.

Moderate hyperopia: $\mathrm{SE} \geqslant+2.00 \mathrm{D}$; mild hyperopia: $+0.50 \mathrm{D} \leqslant \mathrm{SE}<+2.00 \mathrm{D}$; emmetropia: $-0.50 \mathrm{D}<\mathrm{SE}<+0.50 \mathrm{D}$; myopia: $\mathrm{SE} \leqslant-0.50 \mathrm{D}$. 
Table 3 Spherical equivalent refraction and ocular biometric parameters in children aged 12 years, stratified by gender and ethnicity

\begin{tabular}{|c|c|c|c|}
\hline & $\mathrm{n}$ & Mean $( \pm S D)$ & P-value ${ }^{\mathrm{a}}$ \\
\hline \multicolumn{4}{|l|}{ Spherical equivalent (D) } \\
\hline Whole group & 2340 & $0.48( \pm 1.34)$ & - \\
\hline Boys & 1190 & $0.58( \pm 1.16)$ & Referent \\
\hline Girls & 1163 & $0.39( \pm 1.49)$ & 0.04 \\
\hline European Caucasian & 1402 & $0.82( \pm 1.00)$ & Referent \\
\hline East Asian & 349 & $-0.69( \pm 1.92)$ & $<0.0001$ \\
\hline South Asian & 127 & $-0.35( \pm 1.53)$ & $<0.0001$ \\
\hline Middle Eastern & 163 & $0.71( \pm 1.09)$ & 0.03 \\
\hline \multicolumn{4}{|c|}{ Average corneal radius ( $\mathrm{mm})$} \\
\hline Whole group & 2327 & $7.78( \pm 0.25)$ & - \\
\hline Boys & 1181 & $7.83( \pm 0.25)$ & Referent \\
\hline Girls & 1146 & $7.73( \pm 0.24)$ & $<0.0001$ \\
\hline European Caucasian & 1385 & $7.77( \pm 0.25)$ & Referent \\
\hline East Asian & 350 & $7.79( \pm 0.27)$ & 0.008 \\
\hline South Asian & 129 & $7.76( \pm 0.28)$ & 0.9 \\
\hline Middle Eastern & 165 & $7.82( \pm 0.26)$ & 0.009 \\
\hline \multicolumn{4}{|l|}{ Axial length (mm) } \\
\hline Whole group & 2311 & $23.38( \pm 0.85)$ & - \\
\hline Boys & 1174 & $23.58( \pm 0.78)$ & Referent \\
\hline Girls & 1137 & $23.18( \pm 0.86)$ & $<0.0001$ \\
\hline European Caucasian & 1376 & $23.23( \pm 0.75)$ & Referent \\
\hline East Asian & 348 & $23.86( \pm 1.07)$ & $<0.0001$ \\
\hline South Asian & 128 & $23.65( \pm 0.94)$ & $<0.0001$ \\
\hline Middle Eastern & 164 & $23.39( \pm 0.70)$ & 0.002 \\
\hline
\end{tabular}

$\mathrm{D}$, dioptre; $\mathrm{mm}$, millimetre; $\mathrm{SD}$, standard deviation.

${ }^{a}$ Adjusted for cluster-sampling, age, and height.

\section{Anterior chamber depth and lens power}

Mean anterior chamber for the whole group was $3.67 \mathrm{~mm}$, and was deeper in European Caucasian children compared to East Asian children (3.67 vs $3.62 \mathrm{~mm}$, $P=0.047$, adjusting for age, gender, and height.

However, anterior chamber depth in European Caucasian children was similar to that in South Asian children and Middle Eastern children (both $P>0.05$ ). Boys had deeper chambers than girls (3.73 vs $3.61 \mathrm{~mm}, P<0.0001$ ).

Calculated lens power was 22.15D for the whole group, and was weaker in children of East Asian ethnicity than in children of European Caucasian ethnicity (22.03 vs 22.18 D, $P=0.02$ ). Lens power in the European Caucasian group was similar to that in South Asian children and in Middle Eastern children (both $P>0.05$ ). Boys had weaker lens power than girls (21.67 vs 22.65 D, $P<0.0001)$.

\section{Axial length in emmetropia and myopia, differences in two major ethnic groups}

The distribution of axial length among emmetropic children was similar between European Caucasian and

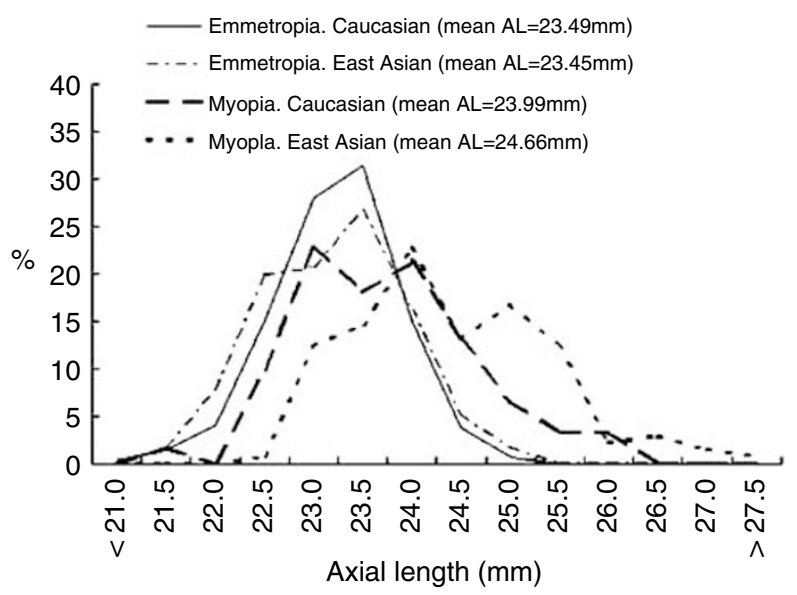

Figure 1 Distribution of axial length among children with emmetropia $(-0.50 \mathrm{D}<\mathrm{SE}<0.50 \mathrm{D})$ and myopia $(\mathrm{SE} \leqslant-0.50 \mathrm{D})$, in children of European Caucasian and East Asian ethnicity. $X$-values represent minimum value of each interval. SE, spherical equivalent refraction; $\mathrm{AL}$, axial length; $\mathrm{D}$, dioptres.

East Asian children, with similar mean axial length (23.49 $\mathrm{mm}$ for European Caucasian and $23.45 \mathrm{~mm}$ for East Asian children, respectively, shown in Figure 1). Among myopic children, there was a wide distribution and overlap of axial length in both European Caucasian and East Asian subgroups; differences between these two ethnic groups included a higher proportion of children with greater axial lengths and a tendency towards longer axial length among the East Asian subgroup. In children with myopia, mean axial length was slightly longer in the East Asian subgroup $(24.66 \mathrm{~mm})$ than in the European Caucasian subgroup ( $23.99 \mathrm{~mm}$ ). Considerable overlap in the distribution of axial length was noted between emmetropic and myopic children.

\section{Discussion}

\section{Prevalence of SE errors}

In this large population-based sample of Sydney children with a mean age of 12.7 years, the prevalence of myopia was $11.9 \%$, whereas the prevalence of moderate hyperopia was $3.5 \%$. The mean SE (+0.49 D) was just within the emmetropic range.

Comparison of refractive error prevalence rates with other studies is difficult due to the use of different definitions, instrumentation, variable use of cycloplegia, plus differences in other population characteristics such as ethnicity, gender, and age distribution. In studies of predominantly European Caucasian children, the reported prevalence for myopia ranges from 11.6 to 49.7\%. ${ }^{13-15,26}$ Junghans and Crewther ${ }^{26}$ reported only a slightly higher prevalence of myopia (14.7\%) in urban Australian children, using non-cycloplegic retinoscopy. 
This method, however, increases measurement variability and is likely to underestimate hyperopia, ${ }^{2}$ emphasising the importance of cycloplegia. In studies among predominantly European Caucasian children in the US, Zadnik ${ }^{15}$ reported a prevalence of myopia of around $20 \%$ for children aged 12 years and Kleinstein et $a l^{14}$ reported a prevalence of $11.6 \%$ for children aged 5-17 years in the Collaborative Longitudinal Evaluation of Ethnicity and Refractive Error. Among 12-13-year-old children in Sweden, Villarreal et al ${ }^{13}$ reported a myopia prevalence of $49 \%$. These values are consistently higher than the low prevalence of myopia in 12-year-old European Caucasian children reported in this study (4.6\%).

The overall prevalence of myopia in the current study was very substantially lower than that reported for similarly aged East Asian children (36.7-78.4\%), 2,3,11,27 using the same definition for myopia (SE $-0.50 \mathrm{D}$ or less). The overall prevalence of myopia in this study was, however, higher than that reported for children in Chile, Nepal, India, and South Africa (Table 4). ${ }^{5-9}$

\section{Ethnic differences in the prevalence of myopia}

In this study, children of European Caucasian ethnicity had both a lower prevalence of myopia and a more hyperopic SE than children of East Asian ethnicity. A new finding was that children of South Asian ethnicity had a similar myopia prevalence and myopic SE as children of East Asian ethnicity. Ethnic differences in myopia have also been reported in other studies among children in school-based settings. ${ }^{12,14}$ Kleinstein et al ${ }^{14}$ reported a higher prevalence of myopia among Asian children $(18.5 \%)$ than White children $(4.4 \%)$, aged 5-17 years. Each ethnic sample (African American, Asian, Hispanic, and White) was predominantly drawn from relatively different environments; therefore, these differences in myopia prevalence cannot be attributed to ethnicity alone. A study of children aged 7-9 years from two schools in Singapore ${ }^{12}$ showed that the prevalence of myopia among Chinese children (37.0\%) was higher than among non-Chinese children (19.9\%). Ethnic associations with myopia may not necessarily indicate a purely genetic influence, but could reflect enduring patterns of behaviour and cultural attitudes that may result in a more myopigenic environment, such as higher levels of more intense near-work and lower levels of outdoor activity.

The prevalence of myopia in East Asian children in the current study is lower than that in other studies among East Asian children in urban areas, where the prevalence of myopia ranges from 48.2 to $60.0 \%$ (Table 4 ). These differences in myopia prevalence among children of East Asian ethnicity suggest that a high prevalence of myopia is not inherently universal. The association of an urbanised environment with myopia development could be mediated by factors such as higher educational attainment and greater levels of near-work, with possible differences in duration and intensity of study between children of urban and rural areas.

\section{Gender differences in myopia}

The higher prevalence of myopia in girls reported in the current study was also described in our 6-year-old cohort, $^{23}$ and is consistent with a number of studies

Table 4 Prevalence of refractive errors among children aged 12 years from selected studies with age-specific data available

\begin{tabular}{|c|c|c|c|c|}
\hline & \multirow[b]{2}{*}{ Country } & \multirow[b]{2}{*}{ Sample size } & \multicolumn{2}{|c|}{ Prevalence (\%) } \\
\hline & & & $\begin{array}{c}\text { Myopia } \\
(S E \leqslant-0.5 D)\end{array}$ & $\begin{array}{l}\text { Moderate hyperopia } \\
\quad(S E \geqslant+2.0 \mathrm{D})\end{array}$ \\
\hline Villareal et $a l^{13}$ & Sweden & 1045 & 49.7 & $8.4^{\mathrm{a}}$ \\
\hline He et $a l^{3}$ & China (urban) & 454 & 49.7 & 2.0 \\
\hline Zhao et $a l^{2}$ & China (semirural) & 704 & $12.0-23.0$ & $1.0-2.0$ \\
\hline Fan et al ${ }^{11}$ & Hong Kong & 1267 & 48.2 & - \\
\hline Lin $e t a l^{27}$ & Taiwan & 920 & $60.0^{\mathrm{b}}$ & - \\
\hline Maul et $a l^{9}$ & Chile & 435 & $4.0-9.0$ & $11.0-13.0$ \\
\hline Goh et $a l^{4}$ & Malaysia & 534 & 24.8 & 0.6 \\
\hline Murthy et $a l^{7}$ & India (urban) & 560 & 9.7 & 5.0 \\
\hline Dandona et $a l^{8}$ & India (rural) & 534 & 4.8 & 0.8 \\
\hline Pokharel et $a l^{5}$ & Nepal & 481 & $1.0-2.0$ & $<1.0$ \\
\hline Naidoo et $a l^{6}$ & South Africa & 476 & 4.4 & 3.2 \\
\hline Current study & Australia & 2353 & 11.9 & 3.5 \\
\hline
\end{tabular}

D, dioptres; SE, spherical equivalent refraction.

${ }^{a}$ Moderate hyperopia defined as $\geqslant 1.0 \mathrm{D}$.

byopia defined as SE $\leqslant-0.25 \mathrm{D}$. 
among Asian, 2,4,10,11 rural Indian, ${ }^{8}$ and Caucasian childhood populations. ${ }^{20}$ No gender differences, however, were found in studies of children in urban India, ${ }^{7}$ South Africa, ${ }^{6} \mathrm{Nepal}^{5}{ }^{5}$ and Chile. ${ }^{9}$

The higher rate of myopia and lower rate of moderate hyperopia in girls in our study is consistent with their lower mean SE; however, the reasons for these findings are unclear. One possible explanation is that girls may perform more near-work than boys; however, recent papers have raised some doubt over the relative importance of near-work as a risk factor for myopia. ${ }^{28}$ Another suggestion is that earlier pubertal changes in girls are responsible; however, in our findings we have shown that mean axial length was shorter in girls than boys, making a hormonal cause for myopia less likely.

\section{Hyperopia}

Hyperopia is an important condition because of its association with amblyopia, strabismus, and anisometropia in children. ${ }^{29}$ Although the prevalence of moderate hyperopia varies among different countries (Table 4), these differences are typically less dramatic than the differences in myopia prevalence. The prevalence of moderate hyperopia in our sample was comparable to that in urban India, ${ }^{7}$ but was higher than rates reported for East Asian countries, ${ }^{2-4,11,27}$ rural India, ${ }^{8}$ and South Africa. ${ }^{6}$

Populations with a high prevalence of myopia generally have a relatively low prevalence of hyperopia (Table 4). This suggests that the decrease in prevalence of moderate hyperopia with age may be due to an overall myopic shift in the population, which, in turn, are associated with age-related physiological changes in ocular biometry. However, in locations such as Nepal, rural India, and South Africa, where the prevalence of myopia is very low, factors other than age-related myopic shift may also contribute to a low prevalence of hyperopia.

\section{Ocular biometry}

Age-specific ocular biometric data for children have been published for older children in the $\mathrm{US}^{17,20}$ and Taiwan. ${ }^{10}$ These reports used ultrasound measurements and provided gender-stratified data but not overall data for each age year, making comparison with our ethnic subgroups difficult. The mean axial length in boys $(23.58 \mathrm{~mm})$ and girls $(23.18 \mathrm{~mm})$ obtained by IOLMaster in our study were actually comparable to those reported by Zadnik et $a l^{20}$ for similarly aged children (23.55 and $23.27 \mathrm{~mm}$ in boys and girls, respectively). Lin et al ${ }^{10}$ reported similar findings for Taiwanese girls $(23.6 \mathrm{~mm})$ but slightly longer mean axial length $(24.1 \mathrm{~mm})$ in
Taiwanese boys, both aged 12 years. Mean axial length for children of East Asian ethnicity in our study was $23.86 \mathrm{~mm}$.

Among studies of children with myopia, mean axial length was generally longer. In the Correction of Myopia Evaluation Trial study, ${ }^{17}$ which only included children with myopia, axial length in those aged 11 years was $24.62 \mathrm{~mm}$ in boys and $24.23 \mathrm{~mm}$ in girls. In younger Singaporean children (ages 7-9 years), axial length measurements obtained using ultrasound for those with low myopia $(23.76 \mathrm{~mm})$ or high myopia $(24.81 \mathrm{~mm})$ were greater than that found in 12-year-old children $(23.38 \mathrm{~mm})$ in the current study.

Our finding that boys generally had a more hyperopic refraction and longer eyes with deeper anterior chambers than girls is consistent with previous studies using ultrasound measurements. ${ }^{10,17}$ Some studies have also reported weaker lens power ${ }^{20}$ and thinner lens ${ }^{10}$ among boys. Although there were highly statistically significant gender differences in mean corneal radius and axial length, the actual differences were quite small ( 0.1 and $0.4 \mathrm{~mm}$, respectively) and translated into only a small difference in SE (0.19D) between boys and girls. Therefore, in clinical terms, the differences of ocular biometry between boys and girls may be considered relatively inconsequential.

\section{Strengths and limitations}

We used random cluster sampling to obtain a large representative sample of children in the Sydney metropolitan region. Both satisfactory response rate, and the use of cycloplegic refraction and standardised measurement protocols contributed to the strengths of this study. By examining a large sample of children within one school year, we are able to control the influences of schooling to a certain extent and make valid comparisons of ocular dimensions between boys and girls, and between ethnic groups. We assigned ethnicity for the child by using data from both parents to increase accuracy and excluded children of mixed race from ethnic comparisons. Ocular biometry measurements were obtained by the IOLMaster, which are considered to be more precise and repeatable than those obtained using ultrasound. ${ }^{21}$ As previous reports have shown that axial length measurement by non-immersion ultrasound are shorter, ${ }^{30}$ IOLMaster measurements were internally adjusted for comparison.

A limitation of this study was the use of calculated lens power. This was based on the Gullstrand-Emsley schematic eye, and assumed a theoretical relationship between ocular components in the adult eye. Measurement of vitreous chamber depth was not performed with the IOLMaster. With a cross-sectional 
design, data on development and progression of myopia are outside the scope of this study. Comparing the current findings in 12-year-old children with our previously published data for 6-year-old children, however, ${ }^{23}$ the older children had a higher prevalence of myopia, longer axial length, longer anterior chamber depth, weaker lens power, and a more myopic SE than the younger children. There was no apparent change in the corneal radius between the two samples.

In summary, in this study of 12 -year-old children, we report a relatively low prevalence of myopia by international standards in age-matched cohorts. There were substantial ethnic differences in the prevalence of different refractive errors and in ocular dimensions within this sample of children from diverse ethnic backgrounds. Among the four major ethnic groups, myopia prevalence ranged from European Caucasian (lowest), Middle Eastern, South Asian, and East Asian (highest) with corresponding range of increasing axial length.

\section{Acknowledgements}

The Sydney Myopia Study is supported by the Australian National Health \& Medical Research Council (Grant No. 253732); the Westmead Millennium Institute, University of Sydney; and the Vision Co-operative Research Centre, University of New South Wales, Sydney, Australia.

\section{References}

1 Pizzarello L, Abiose A, Ffytche T, Duerksen R, Thulasiraj R, Taylor $\mathrm{H}$ et al. Vision 2020: the right to sight. A global initiative to eliminate avoidable blindness. Arch Ophthal 2004; 122: 615-620.

2 Zhao J, Pan X, Sui R, Munoz SR, Sperduto RD, Ellwein LB. Refractive error study in children: results from Shunyi district, China. Am J Ophthalmol 2000; 129: 427-435.

3 He M, Zeng J, Liu Y, Xu J, Pokharel GP, Ellwein LB. Refractive error and visual impairment in urban children in southern china. Invest Ophthalmol Vis Sci 2004; 45: 793-799.

4 Goh PP, Abqariyah Y, Pokharel GP, Ellwein LB. Refractive error and visual impairment in school-age children in Gombak district, Malaysia. Ophthalmology 2005; 112: 678-685.

5 Pokharel GP, Negrel AD, Munoz SR, Ellwein LB. Refractive error study in children: results from Mechi Zone, Nepal. Am J Ophthalmol 2000; 129: 436-444.

6 Naidoo KS, Raghunandan A, Mashige KP, Govender P, Holden BA, Pokharel GP et al. Refractive error and visual impairment in African children in South Africa. Invest Ophthalmol Vis Sci 2003; 44: 3764-3770.

7 Murthy GV, Gupta SK, Ellwein LB, Munoz SR, Pokharel GP, Sanga L et al. Refractive error in children in an urban population in New Delhi. Invest Ophthalmol Vis Sci 2002; 43: 623-631.

8 Dandona R, Dandona L, Srinivas M, Sahare P, Narsaiah S, Munoz SR et al. Refractive error in children in a rural population in India. Invest Ophthalmol Vis Sci 2002; 43: 615-622.

9 Maul E, Barroso S, Munoz SR, Sperduto RD, Ellwein LB. Refractive error study in children: results from La Florida, Chile. Am J Ophthalmol 2000; 129: 445-454.

10 Lin LL, Shih YF, Tsai CB, Chen CJ, Lee LA, Hung PT et al. Epidemiologic study of ocular refraction among schoolchildren in Taiwan in 1995. Optom Vis Sci 1999; 76: 275-281.

11 Fan DS, Lam DS, Lam RF, Lau JT, Chong KS, Cheung EY et al. Prevalence, incidence, and progression of myopia of school children in Hong Kong. Invest Ophthalmol Vis Sci 2004; 45: 1071-1075.

12 Saw SM, Chua WH, Hong CY, Wu HM, Chan WY, Chia KS et al. Nearwork in early-onset myopia. Invest Ophthalmol Vis Sci 2002; 43: 332-339.

13 Villarreal MG, Ohlsson J, Abrahamsson M, Sjostrom A, Sjostrand J. Myopisation: the refractive tendency in teenagers. Prevalence of myopia among young teenagers in Sweden. Acta Ophthalmol Scand 2000; 78: 177-181.

14 Kleinstein RN, Jones LA, Hullett S, Kwon S, Lee RJ, Friedman NE et al. Refractive error and ethnicity in children. Arch Ophthalmol 2003; 121: 1141-1147.

15 Zadnik K. The Glenn A. Fry Award Lecture (1995). Myopia development in childhood. Optom Vis Sci 1997; 74: 603-608.

16 Goss DA, Cox VD, Herrin-Lawson GA, Nielsen ED, Dolton WA. Refractive error, axial length, and height as a function of age in young myopes. Optom Vis Sci 1990; 67: 332-338.

17 Gwiazda J, Marsh-Tootle WL, Hyman L, Hussein M, Norton TT. Baseline refractive and ocular component measures of children enrolled in the correction of myopia evaluation trial (COMET). Invest Ophthalmol Vis Sci 2002; 43: 314-321.

18 Garner LF, Meng CK, Grosvenor TP, Mohidin N. Ocular dimensions and refractive power in Malay and Melanesian children. Ophthalmic Physiol Opt 1990; 10: 234-238.

19 Luo HD, Gazzard G, Fong A, Aung T, Hoh SK, Loon SC et al. Myopia, axial length, and OCT characteristics of the macula in Singaporean children. Invest Ophthalmol Vis Sci 2006; 47: 2773-2781.

20 Zadnik K, Manny RE, Yu JA, Mitchell GL, Cotter SA, Quiralte JC et al. Ocular component data in schoolchildren as a function of age and gender. Optom Vis Sci 2003; 80: 226-236.

21 Lam AK, Chan R, Pang PC. The repeatability and accuracy of axial length and anterior chamber depth measurements from the IOLMaster. Ophthalmic Physiol Opt 2001; 21: 477-483.

22 Huynh SC, Kifley A, Rose KA, Morgan I, Heller GZ, Mitchell P. Astigmatism and its components in 6-year old children. Invest Ophthalmol Vis Sci 2006; 47: 55-64.

23 Ojaimi E, Rose KA, Morgan IG, Smith W, Martin FJ, Kifley A et al. Distribution of ocular parameters and refraction in a population-based study of Australian children. Invest Ophthalmol Vis Sci 2005; 46: 2748-2754.

24 Ojaimi E, Rose KA, Smith W, Morgan IG, Martin FJ, Mitchell P. Methods for a population-based study of myopia and other eye conditions in school children: the Sydney Myopia Study. Ophthalmic Epidemiol 2005; 12: 59-69. 
25 Bennett AG, Rabbetts RB Clinical Visual Optics. Butterworth-Heinemann Ltd: Oxford, 1989.

26 Junghans BM, Crewther SG. Little evidence for an epidemic of myopia in Australian primary school children over the last 30 years. BMC Ophthalmol 2005; 5: 1.

27 Lin LL, Shih YF, Hsiao CK, Chen CJ. Prevalence of myopia in Taiwanese schoolchildren: 1983-2000. Ann Acad Med Singapore 2004; 33: 27-33.

28 Mutti DO, Mitchell GL, Moeschberger ML, Jones LA, Zadnik K. Parental myopia, near work, school achievement, and children's refractive error. Invest Ophthalmol Vis Sci 2002; 43: 3633-3640.

29 Committee for the Classification of Eye Movement Abnormalities and Strabismus. A classification of eye movement abnormalities and strabismus (CEMAS). 2001 pp 1-56 National Eye Institute http://www.nei.nih.gov/ news/statements/cemas.pdf. Accessed January 2007.

30 Carkeet A, Saw SM, Gazzard G, Tang W, Tan DTH Repeatability of IOLMaster biometry in children. Optom Vis Sci 2004; 81: 829-834. 